\title{
CULTURA ORGANIZACIONAL E O PROCESSO DE PLANEJAMENTO E CONTROLE ORÇAMENTÁRIO
}

\section{ORGANIZATIONAL CULTURE AND THE PROCESS OF PLANNING AND BUDGET CONTROL}

\author{
Lígia Maria Heinzmann $^{a}$; Carlos Eduardo Facin Lavarda ${ }^{b}$ \\ ${ }^{a}$ Profissão e instituição: Professora da Universidade Federal de Mato Grosso, UFMT; \\ Doutorada em Ciências Contábeis e Administração pela Universidade Regional de Blumenau FURB \\ Cuiabá, MT-Brasil; E-mail: lheinzmann@al.furb.br \\ ${ }^{b}$ Professor da Fundação Universidade Regional de Blumenau, FURB; \\ Doutorado em Contabilidade - Homologado USP (2009) - pela Universitat Valencia, UV, Espanha; \\ Blumenau,SC-Brasil; E-mail: clavarda@furb.br
}

\begin{abstract}
Resumo
O processo orçamentário é uma etapa de planejamento de uma organização em que os aspectos com relação à cultura empresarial precisam ser observados. O ensaio teórico teve como objetivo analisar os estudos empíricos que relacionam a cultura organizacional e o processo de planejamento e controle orçamentário, em que se buscou identificar as variáveis de cultura organizacional, do processo de orçamento e o método de pesquisa. Os artigos continham as palavras culture e accounting, culture e budget, culture e budgeting control system no título, resumo ou palavras-chave. O termo culture e os demais deveriam estar mencionados de forma articulada. Observou-se convergência nos pontos: variáveis da cultura nacional e organizacional; em algumas variáveis do processo de orçamento, como o planejamento; participação no orçamento; ênfase no orçamento; desempenho geral e desempenho gerencial; método de pesquisa, por meio de elaboração de hipóteses e na utilização de adaptações de instrumentos de outros autores. O ensaio teórico serve como ponto de partida para futuras pesquisas.
\end{abstract}

Palavras-chave:Controle orçamentário, Cultura organizacional, Processo de Planejamento.

\begin{abstract}
The budget process is a planning stage of an organization where the aspects related to the business culture need to be observed. The theoretical essay aims to analyze the empirical studies that relate to organizational culture and the process of planning and budget control, which sought to identify the variables of organizational culture, budget process and research method used. Articles contained the words culture and accounting, budget and culture, culture and budgeting control system in the title, abstract or keywords were selected. The term culture and the others should be mentioned in coordination. It was observed convergence in the following points: national and organizational culture variables; some variables in the budget process, such as planning; budget participation; budget emphasis-overall performance and management performance; research method, through the hypotheses formulation and using instruments adaptations from other authors. This theoretical essay serves as a starting point for future research.
\end{abstract}

Keywords: Budgeting control, Organizational culture, Planning process. 


\section{INTRODUÇÃO}

O processo orçamentário é uma etapa de planejamento de uma organização em que os aspectos com relação à cultura empresarial, a qual envolve a história e o contexto social da organização nos ambientes internos e externos, devem ser observados (LUNKES, 2003; LIMA; JORGE, 2007). Nesse sentido, White, Varadarajan e Dacin (2003) afirmam que a cultura organizacional influencia as percepções de controlabilidade, proporcionando um contexto cognitivo para os tomadores de decisão.

Na perspectiva de identificar como os investigadores estão conduzindo seus estudos sobre a relação entre a cultura organizacional e o processo de planejamento e controle orçamentário, elaborou-se a pergunta norteadora desta pesquisa: quais as convergências e divergências entre os modelos utilizados na literatura internacional?

Neste contexto, propõe-se um ensaio teórico com objetivo de conhecer os estudos empíricos que relacionam a cultura organizacional e o processo de planejamento e controle orçamentário na literatura internacional. Busca-se identificar as variáveis de cultura organizacional e do processo de orçamento apresentadas, além do método de pesquisa utilizado nos artigos.

Para realização do estudo, foi efetuada uma busca no Portal de Periódicos da CAPES (Coordenação de Aperfeiçoamento de Pessoal de Nível Superior), nas Bases de Dados Blackwell, Cambridge, Emerald, ISI - Web of Knowledge, JSTOR, Sciense Direct, Scopus, e Wilson para localizar os artigos, no período compreendido entre 01 de dezembro a 14 de dezembro de 2009. Os artigos de interesse para a presente pesquisa foram os que apresentassem as palavras culture e accounting, culture e budget e culture e budgeting control system no título, no resumo ou nas palavras-chave. Sendo que o termo culture e os demais termos deveriam estar mencionados de forma articulada.

O trabalho justifica-se pela importância do estudo mediante um aprofundamento da relação entre a cultura organizacional e o processo de planejamento e controle orçamentário, assim como o conhecimento das possíveis similaridades e diferenças dos modelos, das variáveis e dos métodos de pesquisa, de forma a delinear futuros trabalhos nesta área.

Além desta introdução, apresenta-se, na segunda parte, uma revisão da literatura, que procura ressaltar as principais referências relacionadas ao tema de pesquisa. Os procedimentos metodológicos são expostos na terceira parte, seguido da análise e da discussão dos dados e, por fim, apresenta-se as considerações.

\section{MARCO TEÓRICO DE REFERÊNCIA}

Apresenta-se a seguir o marco teórico sobre os temas cultura organizacional e processo de planejamento e controle orçamentário.

\subsection{Cultura organizacional}

Considerando as organizações como sistemas socialmente instituídos, compartilhados e apoiados por seus membros, tem-se um padrão de integração que revela algo profundamente enraizado, ou seja, a cultura organizacional, cujos estudos, a partir da década de 70 do século passado, começaram a ganhar profundidade (SMIRCICH, 1983). 
Vários autores estudaram a cultura organizacional como Pettigrew (1979), Smircich (1983), Schein (1984), Trice e Beyer (1984), Trompenaars (1994) e Fleury et al. (2007). Dentre os trabalhos, Schein (1984) é o autor mais citado na abordagem organizacional no que se refere ao conceito de cultura organizacional. Para o autor, cultura organizacional é:

\begin{abstract}
O conjunto de pressupostos básicos que um grupo inventou, descobriu ou desenvolveu ao aprender como lidar com os problemas de adaptação externa e integração interna e que funcionaram bem o suficiente para serem considerados válidos e ensinados a novos membros como a forma correta de perceber, pensar e sentir em relação a esses problemas (SCHEIN, 1984, p. 3).
\end{abstract}

As características da cultura tornam-se gradualmente evidentes à medida que a pessoa se incorpora aos padrões de interação organizacional, da linguagem usada, dos temas explorados nas conversas e dos rituais que fazem parte do dia-a-dia da organização (BERGER; LUCKMANN, 1967).

A cultura organizacional pode ser caracterizada pelo comportamento coletivo e social de seus membros. Os comportamentos coletivos apresentam especificidades diferentes da simples soma dos comportamentos individuais, pois, quando entendido de forma coletiva, o comportamento assume uma totalidade que transcende a simples soma das partes (ZAGO, 2000). A perspectiva cultural abarca as variáveis internas da organização, seu sistema de autoridade, incluindo as estruturas de autoridade formal, sistemas de controle, estruturas de tarefas e regras da organização.

Nesse sentido, a cultura nas organizações se reflete na maneira como as pessoas executam as tarefas, definem os objetivos e administram os recursos necessários para atingir os mesmos. A cultura afeta o modo como as pessoas tomam decisões, pensam, sentem e agem em resposta às oportunidades e ameaças que afetam a organização (BARTHORPE; DUNCAN; MILLER, 2000).

As dimensões de cultura de Hofstede (1980) são o individualismo versus coletivismo, que se distingue tanto ao nível nacional como de culturas organizacionais. Nas sociedades individualistas, prevalece o interesse do indivíduo sobre o interesse do grupo, e nas sociedades coletivistas, prevalece o interesse do grupo. No entendimento de Hofstede (1980) o individualismo é uma oposição ao coletivismo. O coletivismo valoriza ter oportunidades de treinamento, ter boas condições de trabalho e usar as habilidades no trabalho. Nas sociedades individualistas, torna-se necessário praticar uma gestão individualizada.

A dimensão distância de poder está diretamente relacionada com a forma encontrada por diferentes sociedades para lidar com a questão de gerir as desigualdades entre os indivíduos. Em uma empresa, representa a distribuição de autoridade e a centralização da tomada de decisões, ou seja, quanto mais centralizada for a tomada de decisões, maior será a distância de poder. Superiores e subordinados consideram-se desiguais entre si, quando se trata do contexto de grande distância hierárquica. Hofstede (1980) afirma que "as organizações maximizam a centralização de poder num grupo restrito de pessoas". Num contexto de pequena distância hierárquica, subordinados e chefes consideram-se iguais por natureza.

A dimensão masculinidade versus feminilidade nas sociedades tidas como masculinas consiste em oferecer mais oportunidades de reconhecimento, promoção e possibilidades de enfrentar novos desafios. Numa cultura definida como feminina, consiste em oferecer mais oportunidades de ajuda mútua e de contatos sociais. Por sua vez, nas culturas masculinas, o 
chefe toma as suas decisões sozinho, com base em fatos, mais do que apoiado na decisão grupal (HOFSTEDE, 1980).

A dimensão aversão à incerteza analisa a extensão da ansiedade e inquietação que as pessoas sentem ao encarar situações inesperadas ou incertas. "O sentimento de incerteza e as formas de enfrentá-lo fazem parte de herança cultural da sociedade, sendo transmitido e reforçado pelas instituições de base, como a família, a escola e o Estado" (HOFSTEDE, 1991, p. 133).

Conforme Barros e Prates (1996, p. 49), "Hofstede estabeleceu uma dimensão cultural que denominou aversão à incerteza para caracterizar a maneira como as sociedades se comportam em relação ao desconhecido, que gera incertezas e riscos". A gestão da incerteza faz parte de todas as instituições em todos os países, pois o ser humano tem a ansiedade de não saber o que irá acontecer no dia de amanhã, dada a incerteza do futuro (HOFSTEDE, 1980). Assim, as pessoas de diferentes culturas têm comportamentos de risco diferentes quando expostas a uma mesma situação de decisão.

Nos seus estudos, Hofstede (1980) evidenciou que as características culturais de cada uma das filiais eram fortemente influenciadas pelos valores nacionais, predominantes nos países onde essas filiais estavam instaladas. Nos estudos revelou que os valores culturais locais influenciam a cultura organizacional. Hofstede (1991) incluiu a dimensão orientação de longo prazo versus orientação de curto prazo; na prática, a dimensão opõe uma orientação a longo prazo face a uma orientação a curto prazo.

\subsection{Processo de planejamento e controle orçamentário}

O processo de controle orçamentário proporciona o feedback para orientar os gestores sobre estar ou não sendo percebidos como tendo adequado desempenho, e também para a reorientação de suas atividades e prioridades, alimentando o próprio processo de planejamento (FREZATTI et al., 2010). Sendo assim, “um bom controle orçamentário requer o estabelecimento de sistemas e rotinas para assegurar uma clara distinção entre os objetivos dos diversos gestores e dos diversos centros de responsabilidade da organização" (FREZATTI et al., 2010, p. 386).

Por sua vez, os sistemas de controle gerencial influenciam o comportamento das pessoas e a cultura organizacional é o fator interno mais importante que influencia a congruência de objetivos (ANTHONY; GOVINDARAJAN, 2001).

Wickramasinghe e Hopper (2005) comentam que os trabalhos conduzidos por Geert Hofstede influenciaram a pesquisa contábil sobre as diferenças dos sistemas de contabilidade gerencial de acordo com as dimensões da cultura de um país, conhecidos como o coletivismo, masculinidade, distância de poder e aversão à incerteza.

Awasthi, Chow e Wu (1998) observaram que nos trabalhos em equipe, os indivíduos de origem norte-americana selecionavam medidas de desempenho que restringiam as ações individualistas e tomavam decisões sobre o gasto de recursos que promoviam um comportamento voltado à equipe, assim como reconheciam que suas ações exigiam cooperação para maximizar as recompensas, comparativamente ao grupo de indivíduos de origem chinesa. 
Nesse sentido, as variações de como o orçamento é utilizado pelas empresas podem ser explicadas pelo exame de influências externas à organização e que explicam o comportamento de um grupo, como também pelo exame dos aspectos do contexto corporativo, ou seja, ao ambiente de trabalho interno da corporação (MERCHANT, 2007).

Nessa perspectiva, conforme mencionado no trabalho de Frucot e Shearon (1991) a cultura influencia as organizações por meio das estruturas sociais, tais como leis e sistemas políticos e também por meio dos valores, atitudes, comportamento, objetivos e preferências dos participantes. Assim, a visão sobre a realidade dos membros de um grupo deverá afetar a sua percepção do processo orçamentário e os valores sobre a participação nesse processo.

Por exemplo, empresas multinacionais podem modificar os seus sistemas de controle de gestão incluindo sistemas de orçamento para melhor atender as culturas nacionais em que operam (DOUGLAS; WIER, 2005). Frucot e Shearon (1991) mencionam que quando uma técnica de gestão como a participação na elaboração do orçamento é introduzida em um novo ambiente cultural, a aplicação é mais bem-sucedida quando introduzida por gestor local.

Ao examinar a influência da cultura sobre as práticas de controle orçamentário, principalmente em empresas multinacionais, os gestores poderiam compreender como os processos e as práticas do orçamento diferem entre os países, em função das diferenças de normas compartilhadas entre os indivíduos de um grupo, já que "as normas culturais são uma precondição para a predisposição humana, comportamentos e práticas” (UENO; SEKARAN, 1992, p. 660).

\section{PROCEDIMENTOS METODOLÓGICOS}

O ensaio teórico enquadra-se como pesquisa descritiva, pois "os planos de pesquisa descritiva em geral são estruturados e especificamente criados para medir as características descritas em uma questão de pesquisa” (HAIR Jr. et al., 2005, p. 86). Em relação aos procedimentos, enquadra-se como pesquisa bibliográfica e quanto ao método se caracteriza como qualitativo, de acordo com Richardson et al. $(1999$, p. 90) "a pesquisa qualitativa pode ser caracterizada como a tentativa de uma compreensão detalhada dos significados e características situacionais $[\ldots] "$.

Para a realização do estudo, em um primeiro momento, efetuou-se a pesquisa no Portal de Periódicos da CAPES (Coordenação de Aperfeiçoamento de Pessoal de Nível Superior) da seguinte forma: 1) definiu-se que a pesquisa seria realizada nas Bases de Dados: Blackwell; Cambridge; Emerald; ISI - Web of Knowledge; JSTOR; Sciense Direct; Scopus; e Wilson, porque essas bases apresentam as principais publicações na área de Ciências Sociais Aplicadas; 2) selecionou-se os artigos de interesse para a presente pesquisa por meio das palavras culture e accounting, culture e budget e culture e budgeting control system no título, resumo ou palavraschave. Definiu-se que os termos de busca deveriam estar mencionados de forma articulada e encontrou-se 40 artigos disponibilizados em texto completo.

Em um segundo momento, buscou-se identificar os modelos, as variáveis e os métodos de pesquisa utilizados pelos autores. Entre os artigos selecionados, 29 artigos abordaram o tema de forma tangencial, sendo que esses a partir deste momento foram desconsiderados para 
a continuidade da análise.

\section{ANÁLISE E DISCUSSÃO DOS RESULTADOS}

Na sequência apresenta-se um detalhamento dos artigos analisados. No trabalho de Frucot e Shearon (1991) foram selecionados gestores do México, por oferecer um interessante contraste cultural com os EUA nas dimensões identificadas por Hofstede (1980): aversão à incerteza e distância de poder, que são relevantes para a participação no orçamento. Responderam o questionário 83 gerentes. Para a elaboração do mesmo foram feitas algumas adaptações de alguns instrumentos. O questionário desenvolvido por La Rosa (1986) abrange toda a vida do entrevistado, trabalho, economia, família e sociedade em geral (FRUCOT; SHEARON, 1991, p. 87). Está dividido em cinco diferentes escalas, cada uma medindo um aspecto de internalidade ou de externalidade.

Os fatores testados foram agrupados em macro-nível (estrutura organizacional e tecnologia) e em micro-nível (estilo de liderança e personalidade). Para Hofstede (1980) a diversidade cultural pode desempenhar um papel influente no micro-nível.

Para Frucot e Shearon (1991) o controle de gestão é uma variável de micro-nível. A alta posição na hierarquia dos gestores faz com que assumam um papel de liderança e, em decorrência disso, são mais envolvidos no processo de orçamento participativo. Frucot e Shearon (1991) fornecem evidências de que as diferenças culturais podem levar a diferentes respostas no orçamento e que vários grupos dentro de uma mesma cultura podem reagir de forma diferente a um sistema de orçamento específico. O impacto do controle sobre a satisfação gerencial não foi significativa, refletindo uma diferença na cultura. Mas o efeito do controle sobre o desempenho dos gerentes de alto nível foi mais significativo do que seu impacto sobre o desempenho dos gerentes de nível inferior. Na cultura mexicana, os resultados obtidos são diferentes dependendo se a empresa é controlada por estrangeiros.

Ueno e Sekaran (1992) apresentam os resultados de um de estudo sobre a hipótese da influência da cultura em seis aspectos das práticas de controle orçamentário de empresas nos Estados Unidos e Japão, com dados coletados por meio de questionários aplicados a 70 empresas industriais nos Estados Unidos e 149 no Japão. Os autores consideraram seis aspectos do processo do controle orçamentário frequentemente pesquisados para a eficácia do orçamento. Os aspectos são: 1) comunicação e coordenação nos processos de elaboração do orçamento; 2) planejamento de longo prazo versus planejamento de curto prazo; 3 ) estruturação dos processos de orçamento em termos formalizados de regras e procedimentos; 4) folga orçamentária, ou medida em que a folga é inserida no orçamento; 5) controlabilidade dos orçamentos, ou medida em que os gerentes são cobrados ou recebem créditos somente dos itens que estão sob seu controle; 6) avaliação da performance do orçamento ao longo do tempo, isto é, avaliação a curto e longo prazo.

Os resultados de Ueno e Sekaran (1992) indicam que a dimensão individualismo/ coletivismo parece explicar porque as empresas dos EUA em comparação com as Japonesas tendem usar a comunicação e a coordenação de forma mais ampla, constroem folga orçamentária em maior grau e utilizam avaliações de desempenho a longo prazo em menor grau. 
O'Connor (1995) coletou dados por meio de entrevistas e questionários (180 questionários) com gerentes de indústrias de Singapura. No seu trabalho O'Connor (1995) declara que uma preferência cultural por um estilo de gestão específico pode ser criado em um nível organizacional ou nacional. Para uma subsidiária de uma multinacional, com uma influência cultural organizacional de uma sede localizada em um país com uma cultura diferente, pode a questão da diferença entre culturas gerar um conflito, mas também pode ocorrer a interação entre as culturas como no caso de fusões. Já para organizações com alta distância de poder, O'Connor (1995) considera que a participação no orçamento irá resultar em um aumento da ambiguidade dos papéis e uma diminuição de confiança em relação ao superior.

Como resultado, O'Connor (1995) fornece evidências de que as diferenças de cultura organizacional podem levar a respostas diferentes da participação no orçamento e que a natureza da participação no processo foi importante na obtenção de determinados resultados. A distância de poder foi identificada como a principal determinante cultural da participação no orçamento. Em uma cultura de alta distância de poder, o processo de definição do orçamento foi relacionado ao reforço das relações entre superior e subordinado. A cultura organizacional pode influenciar a oportunidade de participação no orçamento.

Lau, Low e Eggleton (1995) analisaram a participação no orçamento e os estilos dos superiores de diversas culturas nacionais por meio de um questionário aplicado em 80 empresas de Singapura com mais de 100 empregados, e obtiveram 112 respostas de gerentes. Como principal resultado, Lau, Low e Eggleton (1995) apresentam a influência da cultura nacional sobre a participação no orçamento. As dimensões de influência foram individualismo e coletivismo, e a distância de poder das culturas nacionais dos países pesquisados. Os resultados reforçam a importância de se analisar o impacto da cultura sobre outros aspectos do sistema de gestão contábil.

Lau, Low e Eggleton (1997) aplicaram um questionário em 80 empresas de Singapura com mais de 100 empregados e 62 empresas da Austrália também com mais de 100 empregados, foram 107 respostas de Singapura e 90 respostas da Austrália. Como resultados, encontraram que a participação no orçamento e a ênfase no orçamento têm relação entre a alta distância de poder e o baixo individualismo.

A alta participação no orçamento em situações com grandes dificuldades nas tarefas está associada a um melhor desempenho gerencial, segundo Lau, Low e Eggleton (1997). Alta ênfase no orçamento e elevada participação estão associadas a um melhor desempenho gerencial em situações de baixa incerteza de tarefas. Por outro lado, reconhecem a necessidade de aperfeiçoar o instrumento de pesquisa utilizado por meio de novas escalas.

Douglas e Wier (2005) realizaram um estudo comparativo entre gerentes dos EUA e da China, em que desenvolveram e testaram um modelo do efeito da cultura sobre o sistema de orçamento. Foram 220 respondentes do EUA e 142 respondentes da China. Os autores constataram que a maioria das visões organizacionais e comportamentais do orçamento deixam de reconhecer os componentes éticos e ignoram o papel da cultura organizacional, já que as diferenças culturais tem implicações para a concepção e eficácia dos sistemas de orçamento.

No modelo de investigação, Douglas e Wier (2005) abordaram a ênfase no orçamento, na participação, e a criação da folga orçamentária. Os dados demonstraram a hipótese de que as diferenças culturais na ideologia ética relacionada com a criação da folga orçamentária somente por parte dos gestores dos EUA. Como resultado, indicam que as empresas multinacionais 
podem modificar os seus sistemas de orçamento para atender as culturas nacionais em que operam e uma compreensão dos custos e benefícios de tais modificações são necessárias para a tomada de decisão.

Leach-Lopez, Stammerjohan e Lee (2009) apresentaram como objetivo a análise da cultura como um fator explicativo da participação no orçamento e a relação no desempenho dos gestores, para isso utilizaram um modelo que permitiu o exame dos efeitos diretos da participação no orçamento sobre o desempenho e os efeitos indiretos entre a participação no orçamento e desempenho, seguindo o modelo LSM de Leach-Lopez et al. (2007). A amostra foi composta de 71 gestores sul-coreanos de empresas industriais de médio e grande porte. Como principal resultado, Leach-Lopez, Stammerjohan e Lee (2009) apresentam que embora haja forte relação entre participação no orçamento e desempenho, os mecanismos de participação são diferentes entre grupos distintos, devido a aspectos culturais. Indicam que a satisfação no trabalho desempenha um papel importante na relação entre a participação no orçamento e o desempenho dos gerentes.

Etemadi et al. (2009) coletaram dados com 256 gerentes de indústrias do Irã. Encontraram evidências de que a aplicação de ferramentas de gestão e técnicas de contabilidade desenvolvidas em países ocidentais para a gestão de desempenho eficaz não é tão útil no contexto iraniano. Com isso, confirmaram os efeitos da interação dos valores culturais com os sistemas de gestão contábil e orçamento. Tanto diferenças culturais de nível nacional como organizacional podem ter um impacto significativo sobre os resultados da aplicação de técnicas de gestão importadas de outros contextos culturais complementam Etemadi et al. (2009).

Na sequência, os trabalhos de Efferin e Hopper, 2007; Yee et al. (2008); Wahyudi (2009) são apresentados em separado em decorrência de apresentarem características distintas dos demais trabalhos, pois o enfoque desses autores está direcionado mais para questões culturais do que para de controle além de utilizarem o método etnográfico e entrevistas.

Efferin e Hopper (2007) analisaram aspectos sociais e culturais na gestão do controle em indústrias de formação chinesa-indonésia. Utilizaram o método etnográfico combinado com teorias que estudam a cultura, diferenças étnicas, história, política e gerenciamento de controle, pois consideraram que estas teorias podem ser complementares. $\mathrm{O}$ interesse dos pesquisadores foi em analisar como a cultura chinesa influencia a gestão do controle.

Nesse sentido, Efferin e Hopper (2007) observam que pesquisas que tem utilizados as construções culturais de Hofstede (1980) tem negligenciado as questões de etnicidade e multiculturalismo, além do que tem dado pouca explicação sobre o que são os valores chineses, do porque eles surgiram, quais são os seus padrões e como eles influenciam os controles nas organizações.

Efferin e Hopper (2007) coletaram dados por meio de entrevistas, análise de documentos, observação participante e etnografia, a partir de questões englobando controle de resultados, controle de ações, controles e valores culturais, etnias e aspectos técnicos das atividades organizacionais. No modelo de análise, utilizaram sete variáveis: 1) pessoas e controle; 2) participação; 3) controles devido à confiança e relações pessoais; 4) recompensas e resultados; 5) recompensas baseadas em valores; 6) incentivos como valores; e 7) planejamento de longo prazo. 
As dimensões de Hofstede (1980) não são adequadas para analisar a cultura chinesa, por esta ser formada por um conjunto diferenciado de valores, como o contexto natural dessa cultura com valores éticos, comportamentais, religiosos (valores descendentes do confucionismo), conforme mencionam Efferin e Hopper (2007). Assim, confirmam achados de pesquisas anteriores que sugerem que os negócios conduzidos por indivíduos de origem chinesa apresentam baixa participação no orçamento, centralização da decisão, tendem a escolher controles subjetivos em relação a um controle objetivo e apresentam pouca orientação para recompensas por resultados e alto uso de recompensas grupais.

Yee et al. (2008) analisaram o impacto que a cultura japonesa tem sobre as previsões orçamentárias e avaliação de desempenho. Considerando a cultura japonesa diferente da cultura ocidental, o trabalho é uma revisão literária que busca definir uma agenda de pesquisa sobre a cultura japonesa e os processos de orçamento. Para testar o instrumento de pesquisa, realizaram um estudo piloto com duas entrevistas. Yee et al. (2008) buscaram conhecer os valores culturais japoneses, especialmente se a orientação coletivista é mantida e reforçada no âmbito das filiais no exterior de empresas multinacionais japonesas.

Como resultados, os autores apresentam evidencias sobre a alta distância de poder: as políticas e processos que as subsidiárias no exterior devem seguir para manter a cultura japonesa; o predomínio do coletivismo sobre o individualismo; e as características da dimensão de masculinidade. Também destacaram que os gerentes são recompensados com base no lucro global da empresa, em consonância com a orientação coletivista japonesa.

Wahyudi (2009) analisou os esforços de gestão de uma instituição de ensino superior privado da Indonésia para substituir o sistema de avaliação de desempenho, com base no controle pessoal e com um sistema de controle orçamentário restrito. Utilizou o método etnográfico com observação participante, entrevistas estruturadas e análise de documentos.

Muitos estudos suportam a teoria de que um novo sistema poderá encontrar dificuldades porque contradiz uma cultura existente, afirma Wahyudi (2009). O autor também apresenta que uma mudança no sistema de controle pode violar normas culturais existentes impactando as práticas gerenciais e os processos de decisão.

\subsection{Convergências e divergências dos trabalhos analisados}

Para analisar as convergências e divergências observou-se: o objetivo; as variáveis de cultura organizacional e as variáveis do processo do orçamento; o método de pesquisa e o modelo adotado nos artigos.

Quanto aos objetivos apresentados, observou-se que os oito trabalhos analisados apresentaram uma relação entre a cultura nacional e/ou organizacional e o processo de controle do orçamento, conforme havia sido determinado no critério de busca dos artigos para a pesquisa (quadro 1).

Todos os trabalhos abordaram a cultura nacional e os trabalhos de O'Connor (1995), Douglas e Wier (2005) e Etemadi et al. (2009) também abordaram a cultura organizacional, usando como referências nos seus trabalhos obras de Hofstede posteriores a 1980. 


\begin{tabular}{|c|l|}
\hline Autor (es) e Ano & \multicolumn{1}{c|}{ Objetivo } \\
\hline Frucot e Shearon (1991) & $\begin{array}{l}\text { Analisar as diferenças culturais que afetam a identificação da inter-relação entre } \\
\text { o controle e a participação no processo orçamentário e como elas afetam o } \\
\text { desempenho gerencial e a satisfação. }\end{array}$ \\
\hline Ueno e Sekaran (1992) & $\begin{array}{l}\text { Analisar o papel da cultura nas preferências e diferenças das práticas de controle } \\
\text { do orçamento em empresas nos Estados Unidos e Japão. }\end{array}$ \\
\hline O'Connor (1995) & $\begin{array}{l}\text { Analisar as diferenças na cultura organizacional entre empresas de manufatura } \\
\text { locais e estrangeiras e como afetam a participação no orçamento em um país de } \\
\text { alta distância de poder (Singapura). }\end{array}$ \\
\hline $\begin{array}{c}\text { Lau, Low, e Eggleton } \\
\text { (1995) }\end{array}$ & $\begin{array}{l}\text { Analisar a participação no orçamento e os estilos dos superiores em diversas } \\
\text { culturas nacionais. }\end{array}$ \\
\hline $\begin{array}{c}\text { Lau, Low e Eggleton } \\
(1997)\end{array}$ & $\begin{array}{l}\text { Investigar a interação entre ênfase no orçamento, a participação e a dificuldade das } \\
\text { tarefas que afetam o desempenho de gestores da Austrália e comparar com gestores } \\
\text { de Singapura. Analisar o efeito da cultura na gestão dos sistemas de controle. }\end{array}$ \\
\hline $\begin{array}{c}\text { Douglas e Wier (2005) } \\
\text { Etemadi et al. (2009) }\end{array}$ & $\begin{array}{l}\text { Analisar o efeito da cultura sobre o sistema de orçamento e suas variáveis, } \\
\text { considerando valores éticos. }\end{array}$ \\
\hline $\begin{array}{c}\text { Leach-Lopez, } \\
\text { stammerjohan e Lee } \\
(2009)\end{array}$ & $\begin{array}{l}\text { Analisar a cultura como um fator explicativo da participação no orçamento e } \\
\text { relação no desempenho de gestores sul-coreanos. }\end{array}$ \\
\hline
\end{tabular}

Quadro 1: Objetivos dos artigos analisados

Com relação às variáveis de cultura (quadro 2), os trabalhos utilizaram as dimensões de Hofstede (1980), sendo que seis trabalhos utilizaram as quatro dimensões: 1) individualismo/ coletivismo; 2) distância de poder; 3) aversão às incertezas; 4) masculinidade/Feminilidade. Os trabalhos que utilizaram essas dimensões foram de Frucot e Shearon (1991); Ueno e Sekaran (1992); O'Connor (1995); Douglas e Wier (2005) incluíram dimensões sobre questões de ética: idealismo e relativismo; Leach-Lopez, Stammerjohan e Lee (2009); Etemadi et al. (2009); Lau, Low e Eggleton (1995) e Lau, Low e Eggleton (1997) utilizaram apenas duas dimensões de Hofstede (1980): individualismo/coletivismo; e distância de poder.

\begin{tabular}{|c|l|}
\hline Autor (es) e Ano & \multicolumn{1}{c|}{ Variáveis de Cultura } \\
\hline Frucot e Shearon (1991) & $\begin{array}{l}\text { Dimensões de Hofstede: 1) individualismo/coletivismo; 2) distância de poder; 3) } \\
\text { aversão às incertezas; 4) masculinidade/feminilidade. }\end{array}$ \\
\hline Ueno e Sekaran (1992) & $\begin{array}{l}\text { Dimensões de Hofstede: 1) individualismo/ coletivismo; 2) distância de poder; 3) } \\
\text { aversão às incertezas; 4) masculinidade/feminilidade. }\end{array}$ \\
\hline O'Connor (1995) & $\begin{array}{l}\text { Dimensões de Hofstede: 1) individualismo/coletivismo; 2) distância de poder; 3) } \\
\text { aversão às incertezas; 4) masculinidade/feminilidade. }\end{array}$ \\
\hline $\begin{array}{c}\text { Lau, Low, e Eggleton } \\
\text { (1995) }\end{array}$ & $\begin{array}{l}\text { Duas Dimensões de Hofstede: 1) individualismo/coletivismo; 2) distância de } \\
\text { poder. }\end{array}$ \\
\hline $\begin{array}{c}\text { Lau, Low e Eggleton } \\
\text { (1997) }\end{array}$ & $\begin{array}{l}\text { Duas Dimensões de Hofstede: 1) individualismo/ coletivismo; 2) distância de } \\
\text { poder. }\end{array}$ \\
\hline $\begin{array}{c}\text { Douglas e Wier (2005) } \\
\text { Leach-Lopez, } \\
\text { aversão às incertezas; 4) masculinidade/feminilidade. } \\
\text { Dimensões sobre questões éticas; idealismo e relativismo. }\end{array}$ & $\begin{array}{l}\text { Dimensões de Hofstede: 1) individualismo/coletivismo; 2) distância de poder; 3) } \\
\text { aversão às incertezas; 4) masculinidade/feminilidade. }\end{array}$ \\
\hline $\begin{array}{c}\text { Stammerjohan e Lee de poder; 3) } \\
\text { (2009) }\end{array}$ & $\begin{array}{l}\text { Dimensões de Hofstede: 1) individualismo/coletivismo; 2) distância de poder; 3) } \\
\text { aversão às incertezas; 4) masculinidade/feminilidade. }\end{array}$ \\
\hline \begin{tabular}{l} 
Etemadi et al. (2009) \\
\hline
\end{tabular}
\end{tabular}

Quadro 2: Variáveis da Cultura 
As variáveis do processo de orçamento que os trabalhos utilizaram foram de quatro a dez variáveis distintas (quadro 3). Entre estas variáveis, o planejamento, a participação no orçamento, a ênfase no orçamento, o desempenho e o desempenho gerencial estão presentes em quase todos os trabalhos.

Com relação ao método de pesquisa (quadro 4), foram elaboradas hipóteses de pesquisa, variando entre quatro e dez hipóteses, com base nas teorias apresentadas nos trabalhos.

\begin{tabular}{|c|l|}
\hline $\begin{array}{c}\text { Autor (es) e Ano } \\
\text { Vrucot e Shearon } \\
\text { (1991) }\end{array}$ & $\begin{array}{l}\text { 1) Tempo na empresa e no cargo; 2) Salário; 3) Participação; 4) Satisfação; } \\
\text { 5) Desempenho; 6) Internalidades (trabalho, economia, família e sociedade em geral). }\end{array}$ \\
\hline $\begin{array}{c}\text { Ueno e Sekaran } \\
\text { (1992) }\end{array}$ & $\begin{array}{l}\text { 1) comunicação e coordenação; 2) planejamento de longo prazo versus de curto prazo; } \\
\text { 3) estruturação dos processos de orçamento em termos de regras e procedimentos; 4) } \\
\text { folga orçamentária; 5) controlabilidade dos orçamentos; 6) avaliação da performance } \\
\text { do orçamento ao longo do tempo. }\end{array}$ \\
\hline $\begin{array}{c}\text { O'Connor (1995) } \\
\text { desvios do orçamento; 3) fatores incontroláveis que explicam os desvios do orçamento; } \\
\text { 4) cooperação na elaboração do orçamento; 5) razões para revisão do orçamento. }\end{array}$ \\
\hline $\begin{array}{c}\text { Lau, Low, e } \\
\text { Eggleton (1995) }\end{array}$ & $\begin{array}{l}\text { 1) participação no orçamento; 2) ênfase no orçamento; 3) incerteza das tarefas; } \\
\text { 4) dificuldade das tarefas; 5) tensão relacionada ao trabalho; 6) performance gerencial. }\end{array}$ \\
\hline $\begin{array}{c}\text { Lau, Low e } \\
\text { Eggleton (1997) }\end{array}$ & $\begin{array}{l}\text { 1) participação no orçamento; 2) ênfase no orçamento; 3) dificuldade das tarefas; } \\
\text { 4) performance gerencial. }\end{array}$ \\
\hline $\begin{array}{c}\text { Douglas e Wier } \\
\text { (2005) }\end{array}$ & Participação no orçamento (variáveis de Merchant, 1981; Onsi, 1973). \\
\hline $\begin{array}{c}\text { Leach-Lopez, } \\
\text { Lee (2009) }\end{array}$ & $\begin{array}{l}\text { 1) participação no orçamento; 2) planejamento; 3) investigação; 4) coordenação; } \\
\text { 5) avaliação; 6) supervisão; 7) pessoal; 8) negociação; 9) representação; 10) satisfação. }\end{array}$ \\
\hline $\begin{array}{c}\text { Etemadi et al. } \\
\text { (2009) }\end{array}$ & $\begin{array}{l}\text { 1) planejamento; 2) investigação; 3) coordenação; 4) avaliação; 5) supervisão; } \\
\text { 6) equipe; 7) negociação; 8) representação. }\end{array}$ \\
\hline
\end{tabular}

Quadro 3: Variáveis do processo orçamentário

Quanto ao instrumento de coleta predominou o uso de questionário. Destacam-se as menções feitas de adaptações realizadas de instrumentos de Mahoney et al. (1963); Hopwood (1972); Milani (1975) e Brownell (1982), por serem mencionados um maior número de vezes. Quanto à adaptação de modelo, no trabalho de Leach-Lopez, Stammerjohan e Lee (2009), mencionam explicitamente o Modelo de Leach-Lopez et al. (2007).

\begin{tabular}{|c|l|}
\hline $\begin{array}{c}\text { Autor (es) e Ano } \\
\text { Frucot e Shearon } \\
\text { (1991) }\end{array}$ & $\begin{array}{l}\text { Método de Pesquisa e Modelo adotado } \\
\text { - Teste de oito hipóteses; - Questionário (adaptado de La Rosa, 1986); Minnesota } \\
\text { de Regressão. }\end{array}$ \\
\hline $\begin{array}{c}\text { Ueno e Sekaran } \\
\text { (1992) }\end{array}$ & - Testaram dez hipóteses; - Questionário (escala de Likert); - Análise Fatorial. \\
\hline O'Connor (1995) & $\begin{array}{l}\text { - Testaram quatro hipóteses; - Entrevista e questionário (adaptado de Milani (1975) e } \\
\text { Brownell (1982); - Escala Likert; - Análise Fatorial. }\end{array}$ \\
\hline $\begin{array}{c}\text { Lau, Low, e } \\
\text { Eggleton (1995) }\end{array}$ & $\begin{array}{l}\text { - Testaram seis hipóteses; - Questionário adaptado do Instrumento de Hopwood (1972); } \\
\text { Van de Ven; Delbecq (1974); Milani (1975) Brownell; Hirst (1986); Brownell; Dunk } \\
\text { (1991); Mahoney et al. (1963); - Escala de Likert; - Regressão Hierárquica. }\end{array}$ \\
\hline $\begin{array}{c}\text { Lau, Low e } \\
\text { Eggleton (1997) }\end{array}$ & $\begin{array}{l}\text { - Testaram seis hipóteses; - questionário adaptado do Instrumento de Hopwood (1972); } \\
\text { Van de Ven; Delbecq (1974); Milani (1975) Brownell; Hirst (1986); Brownell; Dunk } \\
\text { (1991); Mahoney et al. (1963); - Escala de Likert; - Regressão Hierárquica. }\end{array}$ \\
\hline $\begin{array}{c}\text { Douglas e Wier } \\
\text { (2005) }\end{array}$ & $\begin{array}{l}\text { - Testaram sete hipóteses; - Questionário; - Análise Fatorial e Anova. } \\
\text { Leach-Lopez, }\end{array}$ \\
\hline $\begin{array}{c}\text { Stammerjohan e } \\
\text { Lee (2009) }\end{array}$ & $\begin{array}{l}\text { - Testaram seis hipóteses; - Instrumento adaptado de Milani (1975); Mahoney et al. } \\
\text { de Leach-Lopez et al. (2007); - Escala de Likert; - Análise de Correlação e Equações } \\
\text { Estruturais }\end{array}$ \\
\hline $\begin{array}{c}\text { Etemadi et al. } \\
\text { (2009) }\end{array}$ & $\begin{array}{l}\text { - Testaram sete hipóteses; - Instrumento desenvolvido por Tsui (2001) e Milani (1975); } \\
\text { - Regressão múltipla. }\end{array}$ \\
\hline
\end{tabular}

Quadro 4: Métodos de pesquisa 
Os estudos apresentaram, ainda, uma diversidade de técnicas de tratamento e análise dos dados como (quadro 4): regressão hierárquica; regressão múltipla; análise fatorial, Anova; correlação e equações estruturais.

Em síntese, entre os oito trabalhos analisados, existe convergência nos objetivos; nas variáveis de cultura organizacional; em algumas variáveis do processo de orçamento (planejamento; participação no orçamento; ênfase no orçamento; desempenho e o desempenho gerencial); no método de pesquisa, por meio de elaboração de hipóteses e aplicação de questionários e na utilização de adaptações de instrumentos de alguns autores (MAHONEY et al., 1963; HOPWOOD, 1972; MILANI, 1975, BROWNELL, 1982). Verificou-se que existe divergência nas técnicas de tratamento e análise dos dados.

Os trabalhos de Efferin e Hopper (2007), Yee et al. (2008) e Wahyudi (2009) apresentam características distintas dos demais trabalhos analisados. O público alvo foram organizações de origem chinesa-indonésia, japonesa e indonésia. Efferin e Hopper (2007) observam que as pesquisas que têm utilizado as construções culturais de Hofstede (1980) têm negligenciado as questões de etnicidade e multi-culturalismo. Elas apresentam em comum o método utilizado de entrevistas (três trabalhos) e etnografia (dois trabalhos). O enfoque dos trabalhos está direcionado mais para questões culturais do que para de controle.

\section{CONSIDERAÇÕES FINAIS}

O objetivo deste ensaio teórico foi conhecer os estudos empíricos que relacionam a cultura organizacional e o processo de planejamento e controle orçamentário. Identificaram-se as variáveis de cultura organizacional e do processo de orçamento apresentadas e o método de pesquisa utilizado nos artigos.

Quanto à pergunta norteadora da pesquisa: quais as convergências e divergências entre os modelos utilizados na literatura internacional? Pode-se observar que em oito trabalhos analisados existe convergência nos objetivos, nas variáveis de cultura nacional e organizacional, em algumas variáveis do processo de orçamento (planejamento; participação no orçamento; ênfase no orçamento; desempenho geral e o desempenho gerencial), no método de pesquisa, por meio de elaboração de hipóteses e aplicação de questionários e na utilização de adaptações de instrumentos de alguns autores, como Mahoney et al. (1963); Hopwood (1972); Milani (1975) e Brownell (1982). Verificou-se somente a divergência nas técnicas de tratamento e análise dos dados.

Conforme mencionado no referencial teórico e observado nos trabalhos analisados, a cultura influencia as organizações por meio das estruturas sociais, tais como leis e sistemas políticos e também por meio dos valores, atitudes, comportamento, objetivos e preferências dos participantes. Assim, a visão da realidade de membros de um grupo deverá afetar a sua percepção do processo orçamentário e os valores sobre a participação nesse processo (FRUCOT; SHEARON, 1991).

Com base no ensaio teórico apresentado, que serve como ponto de partida para futuras pesquisas que envolvam a cultura organizacional e o processo de planejamento e controle orçamentário de forma articulada, sugere-se alguns questionamentos na perspectiva de futuros trabalhos. Por exemplo, desenvolver uma pesquisa que busque aprofundar os estudos sobre a 
influência da cultura nas práticas de controle orçamentário, no sentido de compreender como os processos e as práticas do orçamento diferem em decorrência de diferenças de normas compartilhadas entre os indivíduos de um grupo.

Algumas questões de pesquisa que poderiam surgir nestes estudos seriam: como a cultura organizacional exerce influência nas práticas de controle do orçamento em empresas brasileiras? A cultura organizacional pode ser um fator explicativo da participação no orçamento e pode afetar o desempenho dos gestores? A cultura organizacional influencia as previsões orçamentárias, quanto à constituição de folga orçamentária? Com relação às dimensões de cultura de Hofstede (1980) e Hofstede (1991), poder-se-ia identificar se quanto maior a distância de poder nas empresas, a constituição de folga orçamentária se faz mais presente? Com relação à dimensão aversão à incerteza, quanto mais presente ela estiver na empresa, mais detalhado será o planejamento do controle orçamentário?

Quanto à limitação desta pesquisa, destaca-se o tipo de busca realizada nas bases de dados do Portal de Periódicos da CAPES, utilizando-se palavras-chave, e a análise de artigos de texto completo, o que pode restringir os resultados obtidos, acarretando a exclusão de artigos que poderiam ter sido inclusos neste estudo.

\section{REFERÊNCIAS}

ANTHONY, Robert, N.; GOVINDARAJAN, Vijay. Sistemas de controle gerencial. São Paulo: Atlas, 2001.

AWASTHI, Vidya N.; CHOW, Chee W.; WU, Anne. Performance measure and resource expenditure choices in a teamwork environment: the effects of national culture. Management Accounting Research, v.9, n 2, p. 119-138, 1998. doi: 10.1006/mare.1998.0073.

BARTHORPE, Stephen; DUNCAN, Rosanna; MILLER, Christopher. The pluralistic facets of culture and its impact on construction. Property Management. v.18, n 5, p. 335-351, 2000.

BARROS, Betânia T. de; PRATES, Marco A. S. O estilo brasileiro de administrar. São Paulo: Atlas, 1996.

BERGER, P.; LUCKMANN, L. The social construction of reality. New York: Donbleday, 1967.

BROWNELL, P. The role of accounting data in performance evaluation, budgetary participation, and organizational effectiveness. Journal of Accounting Research, p. 12-27, 1982.

DOUGLAS, Patricia Casey; WIER, Benson. Cultural and ethical effects in budgeting systems: a comparison of US and chinese managers. Journal of Business Ethics. v.60, p. 159-174, 2005.

EFFERIN, Sujoko; HOPPER, Trevor. Management control, culture and ethnicity in a Chinese Indonesian company. Accounting, Organizations and Society. n 32, p. 223-262, 2007.

ETEMADI, Hossein; DILAMI, Zahra D.; BAZAZ, Mohammad; PARAMESWARAN, Ravi. Culture, management accounting and managerial performance: focus Iran. Advances in Accounting, incorporating Advances in International Accounting. n 25, p. 216-222, 2009.

FLEURY, Maria Teresa L. et al. Cultura e poder nas organizações. 2.ed. São Paulo: Atlas, 2007. 
FREZATTI, F., RELVAS, T. R. S., NASCIMENTO, A. R., JUNQUEIRA, E. R., \& BIDO, D. de S. Perfil de planejamento e ciclo de vida organizacional nas empresas brasileiras. Revista de Administração, v.5, n 4, p. 383-399, 2010.

FRUCOT, Veronique; SHEARON, Winston. Budgetary participation, locus of control, and Mexican managerial performance and job satisfaction. The Accounting Review. v.66, n 1, p. 80-99, 1991.

HAIR, Jr. Joseph F. et al. Fundamentos de métodos de pesquisa em administração. Porto Alegre: Bookman, 2005.

HOFSTEDE, Geert. Culture's consequences: international differences in work-related values. v.5, Sage Publications, 1980.

HOFSTEDE, G. Culture and organizations: software of the mind. New York: McGraw-Hill, 1991.

HOPWOOD, A. G. An empirical study of the role of accounting data in performance evaluation, Journal of Accounting Research, v.10, Supplement, p. 156-82, 1972.

YEE, Cassandra Seow-Ling; OTSUKA, Setsuo; JAMES, Kieran; LEUNG, Jenny Kwai-Sim. Japanese culture and budgeting: a review of the literature and a limited pilot study to illustrate the research agenda. Managerial Auditing Journal. v.23, n 9, p. 873-899, 2008.

LA ROSA, J. Escala de locus de control y autoconcepto: construccion y validacion. Tese Doutorado. Universidad Nacional Autonoma de Mexico, 1986.

LAU, Chong M.; LOW, Liang C.; EGGLETON, IAN R. C. The impact of reliance on accounting performance measures on job related tension and managerial performance: additional evidence. Accounting, Organizations and Society. n 5, p. 359-381, 1995.

LAU, Chong M.; LOW, Liang C.; EGGLETON, IAN R. C. The interactive effect of budget emphasis, participation and task difficulty on managerial performance: a cross-cultural study. Accounting, Auditing and Accountability Journal. n 2, v.10, p. 175-197, 1997.

LEACH-LOPEZ, Maria A L., STAMMERJOHAN, Willian; McNAIR, F. Differences in the role of job relevant information in the budget participation-performance relationship among USA and Mexican managers: a question of culture or communication? Journal of Management Accounting Research. v.19, p. 105-36, 2007.

LEACH-LOPEZ, Maria A. L.; STAMMERJOHAN, Willian; LEE, Kyoo S. Budget participation and job performance of South Korean managers mediated by job satisfaction and job relevant information. Management Research News. v.32, n 3, p. 220-238, 2009.

LIMA, Mariomar de S.; JORGE, José Luiz. O planejamento orçamentário como fator de diferencial competitivo nas organizações: um estudo realizado em uma indústria do segmento eletroeletrônico. Encontro da Associação Nacional dos Programas de Pós-Graduação em Administração, 31. Anais...Rio de Janeiro, 2007.

LUNKES, Rogério, J. Contribuição à melhoria do processo orçamentário empresarial. Tese (Doutorado em Engenharia de Produção) Programa de Pós-graduação em Engenharia de Produção. Universidade Federal de Santa Catarina-UFSC, 2003.

MAHONEY, T.A., JERDEE, T. H; CARROL, S. J. Development of managerial performance: a research approach, South Western Publishing, Cincinnati, OH, 1963.

MERCHANT, Kenneth A. O modelo do sistema de orçamento corporativo: influências no 
comportamento e no desempenho gerencial. RCO-Revista de Contabilidade e Organizações, FEARP/USP. v 1, n 1, set/dez 2007. p. 104-121.

MILANI, K.W. The relationship of participation in budget-setting to industrial supervisor performance and attitudes: a field study. The Accounting Review, p. 274-84, 1975.

O'CONNOR, Neale, G. The influence of organizational culture on the usefulness of budget participation by Singaporean-Chinese managers. Accounting, Organizations and Society. v.20, n 5, p. 383-403, 1995.

PETTIGREW, Andrew, M. On studying organizational culture. Administrative Sciense Quarterly.v 24, n 4. p. 570-581, 1979.

RICHARDSON, Roberto J. et al. Pesquisa social: métodos e técnicas. São Paulo: Atlas, 1999.

SCHEIN, Edgar H. Coming to a new awareness of organizational culture. Sloan Management Review. Winter, p. 3-16, 1984.

SMIRCICH, Linda. Concepts of culture and organizational analisys. Administrative Sciense Quarterly. v.28, n 3, p. 339-358, 1983.

TRICE, Harrison M.; BEYER, Janice, M. Studying organizational cultures through rites and ceremonials. The Academy of Management Review. v.9, n 4, p. 653-669, 1984.

TROMPENAARS, Fons. Nas ondas da cultura: como entender a diversidade cultural nos negócios. São Paulo: Educator, 1994.

UENO, Susumu; SEKARAN, Uma. The influence of culture on budget control practices in the USA and Japan: an empirical study. Journal of International Business Studies. v.23, n 4, p. 659-674, 1992.

WAHYUDI, Imam. From physical to accounting control: a study of accounting change resistance. Journal of Accounting, Organizational Change. n 5, v.5, p. 228-242, 2009.

WICKRAMASINGHE, Danture; HOPPER, Trevor. Acultural political economy of management accounting controls: a case study of a textile mill in a traditional sinhalese village. Critical Perspectives on Accounting. n 16, p. 473-503, 2005.

WHITE, Chris, J.; VARADARAJAN, Rajan, P.; DACIN, Peter, A. Market situation interpretation and response: the role of cognitive style, organizational culture and information use. Journal of Marketing. v.67, n 3, p. 63-79, 2003.

ZAGO, Célia C. Modelo de arquitetura da cultura organizacional - MARCO: as dimensões da cultura organizacional suportadas pela sua inter-relação com as variáveis do comportamento humano. Tese (Doutorado em Engenharia de Produção) Programa de PósGraduação em Engenharia de Produção. Universidade Federal de Santa Catarina Florianópolis: UFSC, 2000. 


\section{ENDEREÇO DOS AUTORES:}

\section{Lígia Maria Heinzmann}

Universidade Federal de Mato Grosso, UFMT.

Av. Historiador Rubens de Mendonça, 3000, Ed. Prive Verona

Bloco B, Apto 602, Bosque da Saúde

78.050-000 - Cuiabá - MT

\section{Carlos Eduardo Facin Lavarda}

Fundação Universidade Regional de Blumenau, FURB.

Programa de Pós-graduação em Ciências Contábeis - FURB.

Rua Antonio da Veiga, 140 Bloco D Sala 202

Victor Konder

89012-900 - Blumenau, SC - Brasil 